\title{
Desensitisation of neutrophil responses by systemic interleukin 8 in cystic fibrosis
}

\author{
Yalei Dai, Taraneh P Dean, Martin K Church, John O Warner, Janis K Shute
}

\begin{abstract}
Background - Inflammation associated with neutrophil infiltration is a commonly observed feature of children with cystic fibrosis. Production of the major neutrophil chemotactic cytokine interleukin 8 (IL-8) is potentially of great importance in the pathology of cystic fibrosis. Concentrations of IL-8 in both sputum and bronchoalveolar lavage fluid have been found to be higher in children with cystic fibrosis than in controls. The IL-8 induced chemotactic response and numbers of IL-8 receptors on peripheral neutrophils obtained from children with cystic fibrosis have been compared with a control group of children.
\end{abstract}

Methods - Cells were isolated from 18 patients with cystic fibrosis (aged 4-20 years) and 13 controls (aged 5-12 years) by dextran centrifugation followed by separation on Lymphoprep. Chemotaxis was assayed using multiwell microchemotaxis chambers and $5 \mu \mathrm{m}$ polycarbonate filters. Filters were fixed and stained with Haema-Gurr for counting. Results were expressed as numbers of neutrophils per high power field (HPF).

Results - At the optimum concentration $\left(1 \times 10^{-8} \mathrm{~mol} / \mathrm{l}\right)$ the number of cells $\mathrm{mig}$ rating were similar for controls $(150$ (12)l HPF) and for the cystic fibrosis group (140 (14)/HPF)). At lower concentrations the numbers of neutrophils migrating were lower for the cystic fibrosis group. Scatchard analysis of ${ }^{125}$ I-labelled IL-8 binding revealed lower numbers of receptors on neutrophils from patients with cystic fibrosis $(22000$ per cell) than from controls (75000 per cell).

Conclusions - Reduced responsiveness to IL-8 of neutrophils from patients with cystic fibrosis is associated with receptor desensitisation as a result of exposure to high systemic levels of IL-8.

(Thorax 1994;49:867-871)

Respiratory failure is the ultimate cause of death for most patients with cystic fibrosis and is the result of chronic pulmonary infection and progressive lung injury. The relation between the underlying genetic defect ${ }^{1}$ and repeated endobronchial infection is not clear, but results in a sustained airway inflammatory response. ${ }^{23}$ Neutrophils are the predominant cells of the alveolar space in patients with cystic fibrosis. It appears that the normally protective and selflimiting inflammatory response is overwhelmed by the continued presence of bacteria and their antigenetically active products in the airways. Activation of neutrophils in endobronchial tissues leads to the release of reactive oxidants and proteases resulting in tissue damage.

Several neutrophil chemoattractants are likely to be involved in the neutrophil infiltration observed in patients with cystic fibrosis. However, the major neutrophil chemoattractant in the lung is interleukin 8 (IL-8), ${ }^{4}$ an $8 \mathrm{kD}$ peptide cytokine. We have recently shown ${ }^{5}$ that elevated levels of IL-8 in sputum and bronchoalveolar lavage fluid samples from children with cystic fibrosis correlate significantly with disease severity. We also measured significantly higher levels of IL-8 in serum samples from children with cystic fibrosis than normal controls. IL-8 in the blood may derive from stimulated endothelial cells, ${ }^{6}$ circulating monocytes, ${ }^{7}$ or T cells. ${ }^{8}$ Alternatively, IL-8 may diffuse into the circulation from sites of inflammation. The synthesis of IL- 8 by various pulmonary cell types including alveolar macrophages, ${ }^{9}$ bronchial epithelial cells, ${ }^{10}$ and fibroblasts ${ }^{11}$ has been demonstrated in vitro. The cellular sources of IL-8 in the airways of patients with cystic fibrosis is, however, unknown. The alveolar macrophage may play a central part in the recruitment of neutrophils to the lung since it produces IL-8 in response to either an exogenous stimulus - that is, bacterialderived cell wall lipopolysac charide - or autocrine stimuli such as TNF- $\alpha$ and IL-1 $\beta$. The latter induces IL- 8 production by bronchial epithelial cells and pulmonary fibroblasts, cells which do not respond to lipopolysaccharides. This stimulus specificity indicates a self-amplifying cytokine network for the production of IL- 8 in the lung which is dependent on an initial lipopolysaccharide challenge.

The in vitro chemotactic response of peripheral neutrophils from patients with cystic fibrosis has previously been shown to be normal for $\mathrm{C}_{5} \mathrm{a}^{12}$ and decreased for $\mathrm{LTB}_{4}{ }^{13}$ as the chemoattractant. The hyporesponsiveness to $\mathrm{LTB}_{4}$ in vitro was thought to result from $\mathrm{LTB}_{4}$ induced deactivation of specific surface receptors in vivo. Since IL-8 dynamically regulates its own receptor expression on human neutrophils, ${ }^{14}$ we investigated the hypothesis that chronic production of IL-8 in cystic fibrosis induces a specific dysfunctional chemotactic response as a result of receptor downregulation.

\section{Methods}

MATERIALS

Chloramine-T, sodium metabisulphite, Sephadex G-15, disodium hydrogen phosphate, so- 
dium dihydrogen phosphate, and bovine serum albumin (BSA) were purchased from Sigma Chemicals (Poole, UK), and Macrodex from Pharmacia (Milton Keynes, UK). Lymphoprep and Hanks balanced salt solution were obtained from GibCo (Paisley, Scotland). Human recombinant IL-8 for iodination was purchased from Bachem UK Ltd (Saffron Walden, Essex), and human recombinant IL-8 for the determination of non-specific binding was the kind gift of Dr Ivan Lindley (Sandoz Forschungsinstitut, Vienna). 125-labelled iodine in sodium hydroxide solution was purchased from Amersham International (Little Chalfont, UK).

\section{PATIENTS}

\section{Chemotaxis experiments}

Eighteen patients with cystic fibrosis (10 males, eight females) of mean age 10 (range 4-20) years participated in the study. Thirteen normal controls were recruited from the paediatric day surgery units (12 males and one female) of mean age 7 (range 5-12) years. Control subjects were not enrolled if they had any form of respiratory disorder or current bacterial, viral, or parasitic infection.

\section{IL-8 receptor assays}

Six patients with cystic fibrosis (two males, four females) of mean age 10 (range 5-12) years and nine controls (eight males, one female) of mean age 12 (range 6-15) years were recruited for this part of the study.

\section{NEUTROPHIL ISOLATION}

Heparinised peripheral venous blood was obtained from all subjects, $5 \mathrm{ml}$ for chemotaxis experiments, $10 \mathrm{ml}$ for receptor assays. Whole blood was mixed with Macrodex (6\% dextran in normal saline) in the volume ratio $2: 1$ and allowed to sediment for 45 minutes at room temperature. The leucocyte rich plasma was collected and layered over an equal volume of Lymphoprep. After centrifugation at $450 \mathrm{~g}$ for 30 minutes at room temperature the mononuclear cell layer was discarded and the granulocyte pellet was harvested from the tube and washed. Erythrocytes were removed by hypotonic lysis using $0 \cdot 2 \%$ sodium chloride for 15 seconds. Isotonicity was restored by adding an equal volume of $1.6 \%$ sodium chloride. The cells were then washed twice more with Hanks' balanced salt solution (HBSS) without calcium and magnesium and finally resuspended in HBSS with calcium and magnesium for neutrophil chemotaxis and in ice cold PBS/ $1 \%$ BSA without calcium and magnesium for receptor assays. The resulting cell suspension contained more than $96 \%$ neutrophils with a viability of more than $95 \%$ as assessed by trypan blue exclusion.

NEUTROPHIL CHEMOTAXIS

Chemotaxis assays were performed in duplicate using 48-well microchemotaxis chambers
(Neuro Probe, Cabin John, Maryland, USA) with $5 \mu \mathrm{m}$ pore size polyvinylpyrrolidone-free polycarbonate membranes. Twenty five $\mu \mathrm{l}$ of the chemoattractant f-MetLeu-Phe (fMLP) $\left(10^{-4}-10^{-10} \mathrm{~mol} / \mathrm{l}\right)$ or IL-8 $\left(6 \times 10^{-8}-10^{-10} \mathrm{~mol} / \mathrm{l}\right)$ diluted in HBSS with calcium and magnesium were placed in the bottom chamber and $50 \mu \mathrm{l}$ of neutrophil suspension $\left(10^{6}\right.$ cells $\left./ \mathrm{ml}\right)$ were added to the top chamber. The chambers were incubated for one hour at $37^{\circ} \mathrm{C}$ in a humidified incubator with $5 \% \mathrm{CO}_{2}$. After incubation, non-migrated cells on top of the filter were scraped off and the filter was fixed in methanol for 10 seconds. The filter was air dried and migrated cells stained with Haema-Gurr stain. Neutrophils which migrated to the lower side of the filter were counted using a $400 \times$ magnification in five random high power fields. Experiments were performed in duplicate for each variable and the mean determined. The results were expressed as number of neutrophils/high power field.

\section{IL-8 RECEPTOR ASSAYS}

Human recombinant IL-8 was iodinated by the chloramine-T method as previously described. ${ }^{15}$ Iodinated IL-8 was eluted from a $1 \mathrm{ml}$ bed of Sephadex G-15 in PBS/ $1 \%$ BSA, and remaining unbound ${ }^{125} \mathrm{I}$ removed by dialysis overnight against one litre PBS, with one change of buffer, in a small sac of benzoylated dialysis tubing with a molecular weight cut off at 3500 (Sigma Chemicals, UK). Covalent binding of the label was checked by trichloroacetic acid $(10 \%)$ precipitation and in all preparations there was no free ${ }^{125}$ I. Iodinated IL- 8 has a specific activity of $350-500 \mathrm{Ci} / \mathrm{mmol}$.

Aliquots of neutrophil suspension $\left(10^{6}\right.$ cells $)$ in $\mathrm{PBS} / 1 \% \mathrm{BSA}$ were pipetted into Eppendorf tubes, and increasing concentrations $(0.06-0.8 \mathrm{nmol} / \mathrm{l})$ of ${ }^{125} \mathrm{I}$-labelled IL- 8 in the absence and presence of 1000 -fold excess unlabelled IL-8 were added to a final volume of $200 \mu \mathrm{l}$. Incubations were for 60 minutes at $4^{\circ} \mathrm{C}$ to avoid ligand internalisation. After incubation, cells were washed three times with ice cold PBS. Radioactivity was determined in an LKB Wallac multigamma counter (counting efficiency $76 \%$ ). Non-specific binding was determined in the presence of unlabelled IL-8 and specific binding was defined as total binding minus non-specific binding.

\section{DATA ANALYSIS}

All experiments were carried out in duplicate. Statistical analysis was performed on the Minitab computer using the Mann-Whitney test.

\section{Results}

\section{CHEMOTAXIS}

Chemotactic responses of peripheral neutrophils to IL-8 and fMLP in patients with cystic fibrosis and controls are depicted in 

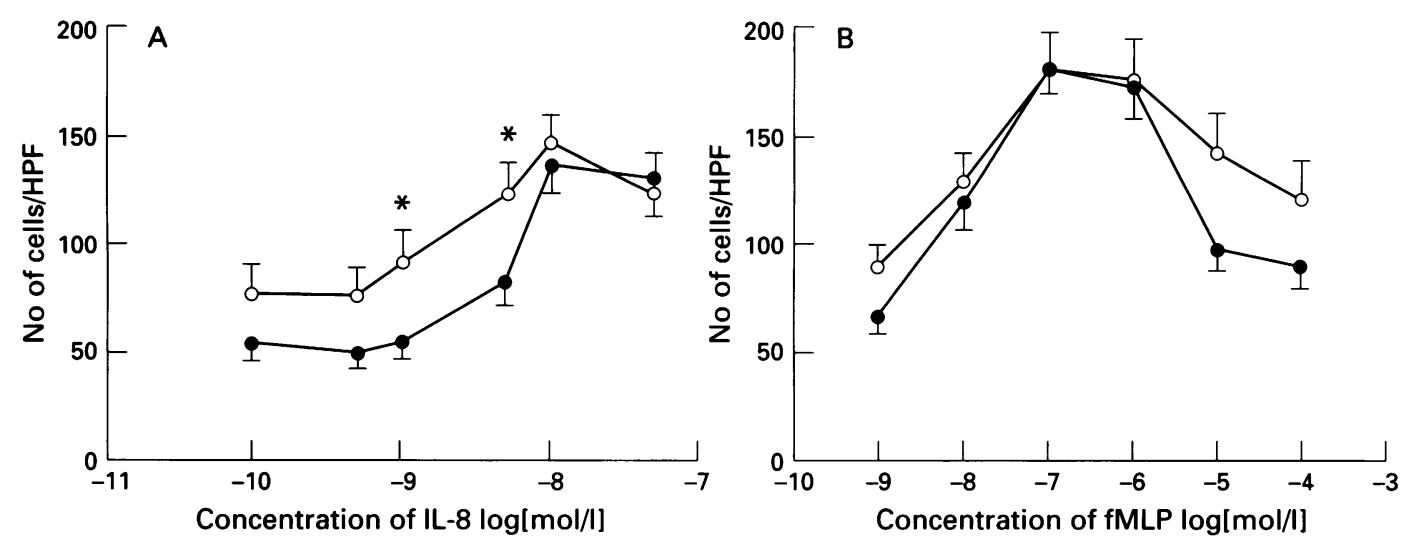

Figure 1 Dose-response curves of human neutrophils (expressed as number of cells/high power field (HPF)) to a range of concentrations of (A) IL-8 and (B) fMLP in the multiwell chemotaxis assay. The results are expressed as mean (SE) from 18 patients with cystic fibrosis (O) and 13 controls (O).

fig 1. The dose-response curves of both the cystic fibrosis and control group showed maximum migration occurring at $10^{-8} \mathrm{~mol} / 1 \mathrm{IL}-8$. The mean (SE) number of cells/high power field migrating at this optimum concentration was not significantly different between the cystic fibrosis and control group (140 (14) and 150 (12), respectively). However, at suboptimal concentrations $\left(1 \times 10^{-9}\right.$ and $\left.6 \times 10^{-9} \mathrm{~mol} / \mathrm{l}\right)$ the number of migrating neutrophils from patients with cystic fibrosis was significantly decreased compared with the control group $(\mathrm{p}<0.05)$.

Figure 1B shows the dose-response curves of both the cystic fibrosis and the control group towards fMLP with maximum migration occurring at $10^{-7} \mathrm{~mol} / \mathrm{l}$. The number of cells migrated at this optimum concentration was not significantly different between the cystic

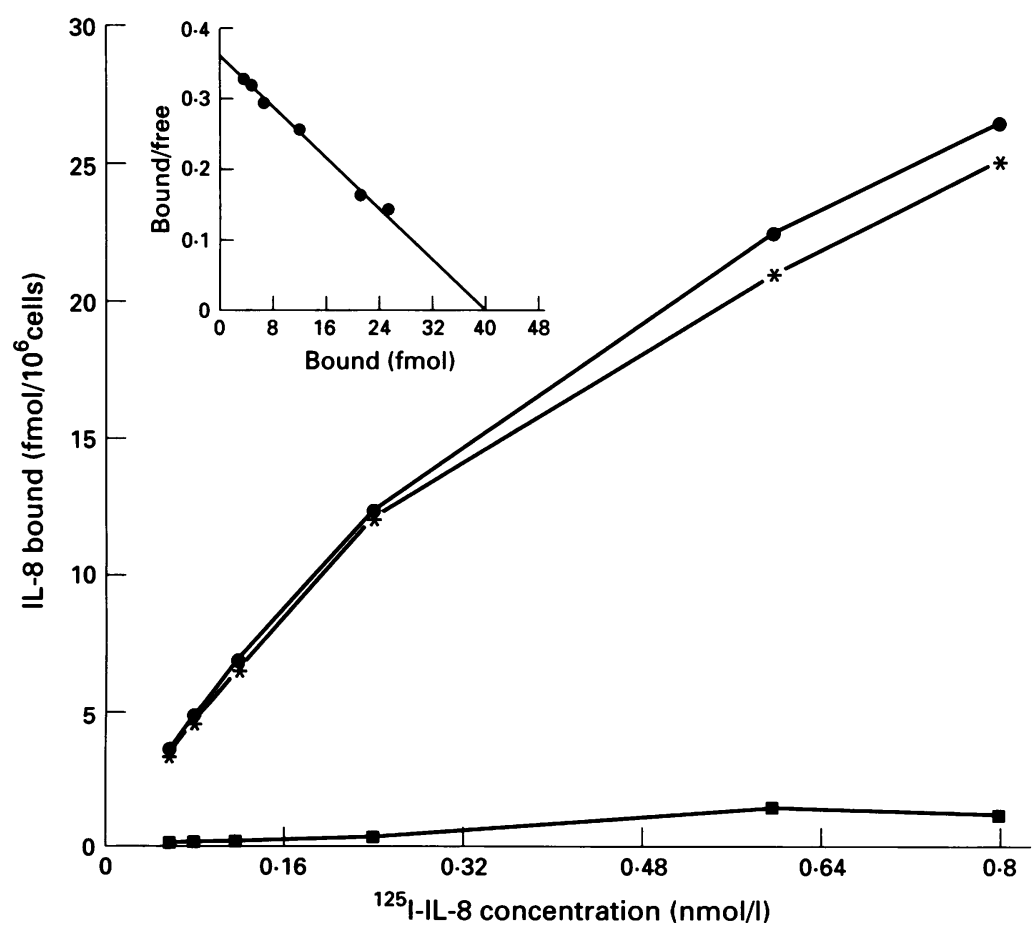

Figure 2 Typical steady state binding of ${ }^{125}$ I-labelled IL-8 to neutrophils from a patient with cystic fibrosis. The specific binding $\left(^{*}\right)$ was calculated as the difference between total binding (O) and non-specific binding (U). Each data point is the mean of duplicate determinations. The insert shows the Scatchard analysis of the binding data. fibrosis and control group (182(12) and 182 (16), respectively).

\section{RECEPTOR ASSAYS}

The dissociation binding constants $(\mathrm{KD})$ and the numbers of IL-8 receptors on the surface of the neutrophils were determined by Scatchard analysis. Figure 2 shows typical Scatchard analyses for neutrophils obtained from one of the patients with cystic fibrosis. It illustrates the binding of ${ }^{125} \mathrm{I}$-labelled IL-8 to neutrophils as a function of the radioligand concentration, and it is clear that non-specific binding was less than $5 \%$ of the total bound. Curve fitting, assuming the presence of a single class of binding sites, gave mean $\mathrm{KD}$ of $12.7(4 \cdot 7)$ $\times 10^{-10} \mathrm{~mol} / 1$ and $19 \cdot 3(7 \cdot 2) \times 10^{-10} \mathrm{~mol} / 1$ for the cystic fibrosis and control group, respectively. There was no significant difference in the IL-8 receptor affinity between the two groups (fig 3). On the other hand, the patients with cystic fibrosis had a significantly lower number of IL-8 receptors (22 198 (2884) receptors/cell) than the controls (75 698 (15 637) receptors/cell) (fig 4).

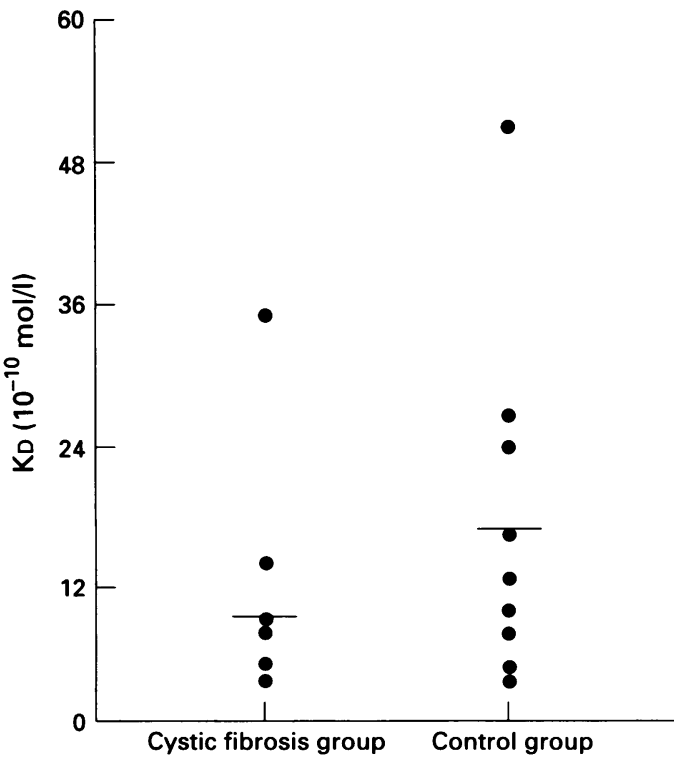

Figure 3 Comparison of the dissociation binding constant for IL-8 binding to neutrophils in six children with cystic fibrosis and six controls $(p=N S)$. Bars indicate median values. 


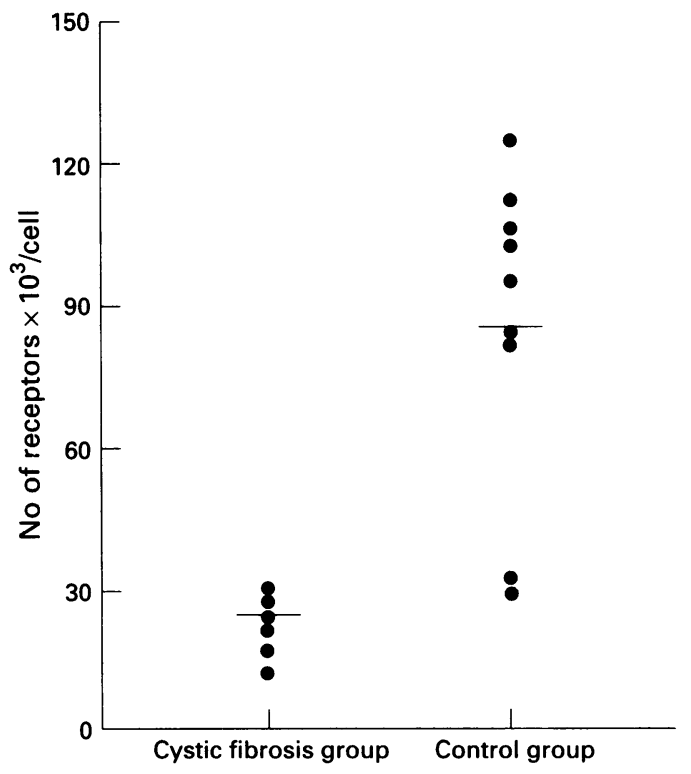

Figure 4 Comparison of the number of $I L-8$ receptors/cell in six children with cystic fibrosis and six controls $(p<0.05)$. Bars indicate median values.

\section{Discussion}

Chemoattractant-induced desensitisation of cellular responses occurs by several mechanisms including decrease in receptor number or downregulation, modification of $\mathrm{G}$ protein or effector function, or depletion of messengers or their precursors. ${ }^{16}$ Our experiments have shown that the chemotactic responsiveness of neutrophils from patients with cystic fibrosis compared with normal subjects is significantly decreased with respect to IL-8, but not fMLP. We have also shown that the number and $\mathrm{KD}$ of specific IL-8 receptors on neutrophils from normal children is of the same order ( $75000 /$ cell with $\mathrm{KD} 2 \times 10^{-9} \mathrm{~mol} / \mathrm{l}$ ) as previously reported - that is, $75000 /$ cell with $\mathrm{KD}$ $4 \times 10^{-9} \mathrm{~mol} / 1,{ }^{15}$ and that neutrophils from children with cystic fibrosis express a lower number (22 000/cell) with a single type of high affinity binding which is not significantly different from normal. IL-8 binding to neutrophils rapidly downregulates receptor expression via internalisation of the ligand-receptor complex. ${ }^{14}$ Removal of IL- 8 from the medium resulted in the rapid reappearance of receptors on the cell surface, and the rapid recycling of IL-8 receptors was therefore proposed to be essential for the chemotactic response of neutrophils. ${ }^{14}$ We have previously shown elevated levels of IL-8 $\left(5 \times 10^{-10}\right)$ in the serum of patients with cystic fibrosis, ${ }^{5}$ indicating that neutrophils in the circulation of patients with cystic fibrosis are chronically exposed to higher concentrations of this cytokine. We speculate, therefore, that the chemotactic hyporesponsiveness of peripheral neutrophils in patients with cystic fibrosis is due to downregulation of surface receptor expression, without a change to a lower affinity state, as a result of prior exposure to elevated levels of free IL-8 in the circulation.

The previously reported decrease in neutrophil chemotactic responsiveness to $\mathrm{LTB}_{4}$ in cystic fibrosis was similarly proposed to be consistent with a specific decrease of receptormediated response to $\mathrm{LTB}_{4}$, rather than a generalised abnormality in neutrophil function, as a result of exposure to local high concentrations of $\mathrm{LTB}_{4}$ as cells pass through the pulmonary circulation. ${ }^{13}$ The greatest difference between cystic fibrosis and normal neutrophil responses was seen at the optimum concentration of $\mathrm{LTB}_{4}$ $\left(10^{-8} \mathrm{~mol} / \mathrm{l}\right) .^{13}$ In contrast, we observed a significantly reduced response to IL- 8 only at suboptimal concentrations. The accuracy and sensitivity of gradient detection is reduced when receptor density is reduced ${ }^{16}$; therefore in low attractant concentrations the response of neutrophils from patients with cystic fibrosis is reduced compared with normal. However, at the highest concentration of IL- 8 the response of normal and cystic fibrosis neutrophils is not significantly different since detection of steep concentration gradients is independent of the number of receptors, but correlates with the difference in receptor occupancy across the cells as it orientates in the gradient. ${ }^{16}$ In view of the steep IL-8 concentration gradient across the lung tissue of patients with cystic fibrosis 5 it is unlikely that receptor downregulation by systemic IL-8 will limit neutrophil recruitment into the lung. As in previous studies ${ }^{13}$ we measured no difference in chemotactic responsiveness to fMLP, indicating a specific effect of IL-8. Desensitisation to different chemoattractants at moderate concentrations is independent and specific to the chemoattractants. $^{16}$ Non-specific desensitisation occurs only at high concentrations of ligand that is, at serum concentrations of IL- 8 higher than we measured in cystic fibrosis. ${ }^{5}$

In addition to systemic effects, evidence that in situ generated mediators regulate neutrophil function in inflamed tissue has been reported. ${ }^{17}$ Neutrophils infiltrating skin pustules in a patient with relapsing bullous staphyloderma were dysfunctional compared with circulating neutrophils when chemotaxis, degranulation, respiratory burst, and $\mathrm{LTB}_{4}$ production were measured in response to IL-8 and C5a. It was suggested that the impaired responsiveness to proinflammatory stimuli of neutrophils migrating into pustules was the result of specific deactivation for receptor-dependent stimuli. The responses of circulating neutrophils in this patient were normal, indicating that the peripheral (intraepidermal) location of the disease restricted the pathological events to the skin. Intraepidermal accumulation of neutrophils is also characteristic of psoriasis, and several recent studies indicate a role for IL-8 in the inflammatory cell infiltration in this disease. ${ }^{18-20}$ A study of IL-8 receptors in normal and psoriatic neutrophils found a slightly raised receptor density in psoriatic neutrophils which was proposed to contribute to neutrophil accumulation in psoriatic skin. ${ }^{21}$ The implication, as for pustulosis, is that IL-8 generated locally influences neutrophil function, and that systemic IL- 8 concentrations are not elevated in these conditions.

Free IL-8 is undetectable $\left(10^{-12} \mathrm{~mol} / \mathrm{l}\right)$ in normal serum samples where it is complexed with a specific high affinity autoantibody of the IgG class. ${ }^{22}$ IL-8 binding to blood neutrophils would inhibit the neutrophil response to a chemotactic gradient; however, the auto- 
antibody prevents the binding of IL-8 to neutrophils after it diffuses into the circulation from the site of production. Following intravenous injection of lipopolysaccharide serum concentrations of free IL- 8 have been found to rise to a peak of $500-900 \mathrm{pg} / \mathrm{ml}$ $\left(\sim 10^{-10} \mathrm{~mol} / \mathrm{l}\right)$ within three hours. ${ }^{23}$ It appears that the rapid response to such a powerful stimulus for IL-8 secretion overwhelms the protective IgG mechanism normally limiting free IL-8 levels. Levels of autoantibody have been shown to adapt to an increase in the circulating load of IL-8 - for example, in rheumatoid arthritis. ${ }^{24}$ In cystic fibrosis it appears, however, that either autoantibody levels which are sufficient to limit free IL-8 in normal individuals are ineffective in the presence of sustained release of IL- 8 from inflamed lung tissue, or increased levels of autoantibody are induced in patients with cystic fibrosis which are nevertheless unable to neutralise the circulating IL-8 load. We are currently investigating these possibilities.

This work was sponsored by grants from the MRC and the Cystic Fibrosis Trust in Great Britain. The authors than Sandoz Forschunginstitut for providing IL-8 and IL-8 antibodies for the assays.

1 Kerem BS, Rommens JM, Buchana JA, Markiewicz D, Cox TK, Chakravati A, et al. Identification of the cystic fibrosis gene: genetic analysis. Science 1989;245:1073-9.

2 Elborn JS, Shale DJ. Lung injury in cystic fibrosis. Thorax 1990;45:97-3.

3 Warner JO. Cystic fibrosis. Br Med Bull 1992;48:893-912.

4 Kunkel SL, Standiford T. Kasahara K, Strieter M. Interleukin-8 (IL-8): the major neutrophil chemotactic factor in the lung. Exp Lung Res 1991;17:17-23.

5 Dean TP, Dai Y, Shute JK, Church MK, Warner JO. IL-8 concentrations are elevated in bronchoalveolar lavage, sputum and sera of children with cystic fibrosis. Pediat Res 1993;34:159-61.

6 Shröder J-M, Christophers E. Secretion of novel and homologous neutrophil-activating peptides by LPSstimulated human endothelial cells. F Immunol 1989 142:244-51.

7 Schröder J-M, Mrowietz U, Christophers E. Identification of different charge species of a human monocyte derived activating peptide (MONAP). Biochem Biophys Res Commun 1988;152:277-84.

8 Schröder J-M, Mrowietz U, Christophers E. Purification and partial biological characterisation of a human lymphocyte derived peptide with potent neutrophil stimulating activity. f Immunol 1988;140:3534-40.

9 Rankin JA, Sylvester I, Smith S, Yoshimura T, Leonard EJ Macrophages cultured in vitro release leukotriene $B_{4}$ and neutrophil attractant/activation protein (interleukin 8) sequentially in response to stimulation with lipopolysaccharide and zymosan. 7 Clin Invest 1990;86:1556polys

10 Standiford TJ, Kunkel SL, Basha MA, Chensue SW, Lynch JP, Taews GB, et al. Interleukin-8 gene expression by a pulmonary epithelial cell line. A model for cytokine networks in the lung. $\mathcal{F}$ Clin Invest 1990;86:1945-53.

11 Rolfe MW, Kunkel SL, Standiford TJ, Chensue SW, Allen $\mathrm{RM}$, Evanoff $\mathrm{HL}$, et al. Pulmonary fibroblast expression of interleukin-8. A model for alveolar macrophage-derived cytokine networking. Am $\mathcal{F}$ Respir Cell Mol Biol 1991;5: 493-501.

12 Church JA, Kens TG, Wange C-I, O'Neal M, Richards W. Normal neutrophil and monocyte chemotaxis in patients with cystic fibrosis. 7 Pediatr $1979 ; 95: 272-4$.

13 Lawrence RH, Sorrell TC. Decreased polymorphonuclear leucocyte chemotactic response to leukotriene $B_{4}$ in cystic fibrosis. Clin Exp Immunol 1992;89:321-4.

14 Samanta AK, Oppenheim JJ, Matsushima K. Interleukin-8 (monocyte derived neutrophil chemotactic factor) dynamically regulates its own receptor expression on human neutrophils. F Biol Chem 1990;265:183-9.

15 Grob PM, David E, Warren TC, De Leon RP, Farina PR, Homon CA. Characterisation of a receptor for human monocyte-derived neutrophil chemotactic factor/interleukin-8. F Biol Chem 1990;265:8311-16.

16 Devreotes PN, Zigmond SH. Chemotaxis in eukaryotic cells: a focus on leukocytes and Dictyostelium. Ann Rev Cell Biol 1988;4:649-86.

17 Mrowietz U, Schröder J-M, Brasch J, Christophers E. Infiltrating neutrophils differ from circulating neutrophils filtrating neutrophils differ from circulating neutrophils when stimulated with C5a, NAP

18 Schröder J-M, Christophers E. Identification of a C5a des arg and an anionic neutrophil activating peptide (ANAP) in psoriatic scales. F Invest Dermatol 1986;87:53-8.

19 Antilla HSI, Reitamo S, Erkko P, Ceska M, Moser B, Baggiolini M. Interleukin-8 immunoreactivity in the skin of healthy subjects and patients with palmoplantar pustulosis and psoriasis. $\mathcal{F}$ Invest Dermatol 1992;98: 96-101.

20 Barker NNWN, Griffiths CEM NAP-1/IL-8 immunoreactivity in normal and psoriatic skin. I Invest Dermatol 1991;97:606-7.

21 Arenberger P, Kemény L, Süss R, Michel G, Peter RU, Ruzicka T. Interleukin-8 receptors in normal and psoriatic polymorphonuclear leukocytes. Acta Derm Venereol (Stockh) 1992;72:334-6.

22 Sylvester I, Yoshimura T, Sticherling M, Schröder J-M Ceska M, Peichl P, et al. Neutrophil attractant protein-1 immunoglobulin $\mathrm{G}$ immune complexes and free antiNAP-1 antibody in normal human serum. $\mathcal{F}$ Clin Invest 1992;90:471-81.

23 Martich GD, Danner RL, Ceska M, Suffredini AF. Detection of interleukin-8 and tumor necrosis factor in normal humans after intravenous endotoxin. The effect normal humans after intravenous endo

24 Peichl $P$, Ceska $M$, Braell $H$, Effenburger F, Lindley IJD. Human neutrophil activating peptide/interleukin 8 acts as an autoantigen in rheumatoid arthritis. Ann Rheum Dis 1992;51:19-22. 